\title{
Experimental study on the dewatering behavior of the dredged mud with horizontal drainage by siphon method
}

\author{
Jun Tong 1 • Noriyuki Yasufuku ${ }^{2} \cdot$ Kiyoshi Omine $^{3} \cdot$ Taizo Kobayashi $^{4}$
}

\begin{abstract}
The disposal of the dredged mud has become a worldwide problem recently. There are urgent demands for developing alternatives to dispose the dredged material in a more economical and environment-friendly manner. In this paper, siphon method is proposed to dewater the high-water-content dredged mud with horizontally installed plastic drainage plate. A series of parallel tests are conducted to preliminarily investigate the dewatering and strength behavior of the dredged mud with vacuum and siphon methods, respectively. On the basis of the test results, siphon method is proved to be an effective and energyfree approach to dewater the dredged slurry.
\end{abstract}

Key words: dredged mud, dewatering, horizontal drainage, siphon method

\section{Introduction}

Dredging is essential for the maintenance and development of ports, harbors and waterways for navigation, remediation and flood management. Dredging of these waterways creates large volumes of dredged material. The material can be a valuable resource although much of it is currently disposed because of economic, logistical or environmental constraints. Whereas, in many countries disposal is becoming more and more difficult owing to the lack of space as well as environmental concerns. Therefore, developing technique for dewatering to reducing the volume of dredged material is of significant necessity. However, most of traditional dewatering methods for the dredged material are featured by high energyconsumption or environmental harm ${ }^{[1]}$. New alternatives are urgently demanded to treat the dredged material environmentally-friendly and effectively. As for the high-water-content dredged slurry, horizontal drainage could significantly increase the dewatering contact area between the drainage material and the mud. In this paper, a new dewatering method-siphon dewatering method with horizontally installed drainage plate is proposed, and the availability and effectiveness of the new method are preliminarily investigated ${ }^{[2]}$.

\section{Test scheme}

A series of laboratory tests are conducted to comparatively investigate the consolidation and strength behavior of the mud under vacuum and siphon conditions. The test scheme includes 2 groups of comparative vacuum and siphon tests with horizontally installed drainage plate, as illustrated in Table 1. The siphon and vacuum dewatering conditions can be illustrated in Figure 1(a), (b).

Table 1 Test scheme

\begin{tabular}{ccccc}
\hline $\begin{array}{c}\text { Test } \\
\text { name }\end{array}$ & $\begin{array}{c}\text { Dewatering } \\
\text { method }\end{array}$ & $\begin{array}{l}\text { Pattern of } \\
\text { installed } \\
\text { drainage } \\
\text { plate }\end{array}$ & $\begin{array}{c}\text { Initial } \\
\text { dewatering } \\
\text { pressure(kPa) }\end{array}$ & $\begin{array}{c}\text { Initial } \\
\text { water } \\
\text { content } \\
(\%)\end{array}$ \\
\hline V-1 & Vacuum & & & \\
V-2 & Horizontal & 30 & 92 \\
\cline { 1 - 2 } S-1 & Siphon & & & \\
\hline
\end{tabular}

\section{Test sample and equipments}

The test sample used in the study was taken from Island city, Fukuoka city, Japan. According to the Unified Soil Classification System, the soil can be categorized as MH. Its basic physical properties are presented in Table 2 . The illustration for the test equipments is shown in Figure 1. The test equipments mainly comprise of perpex tanks, a plastic drainage plates, connectors and plastic pipe, as well as a micro-vane shear apparatus. As shown in Fig. 1 (c), the length, width and thickness of the drainage plate

\footnotetext{
${ }^{1} \mathrm{PhD}$ student, Department of Civil Engineering, Kyushu University, Fukuoka 819-0395, JAPAN Email:tongjun888@gmail.com

${ }^{2}$ Professor, Department of Civil Engineering, Kyushu University, Fukuoka 819-0395, JAPAN

${ }^{3}$ Associate Professor, Department of Civil Engineering, Kyushu University, Fukuoka 819-0395, JAPAN

${ }^{4}$ Assistant Professor, Department of Civil Engineering, Kyushu University, Fukuoka 819-0395, JAPAN
} 
are $17 \mathrm{~cm}, 9.6 \mathrm{~cm}$ and $3.9 \mathrm{~mm}$, respectively. It is installed in the right center of the bottom of the perspex tank horizontally. For the vacuum dewatering tests, the applied vacuum pressure is $30 \mathrm{kPa}$. For the siphon dewatering tests, a $3 \mathrm{~m}$ long plastic pipe full-filled with de-aired water is utilized to yield $30 \mathrm{kPa}$ initial water head difference, which is equivalent to the corresponding vacuum pressure. And the micro-vane shear apparatus is utilized to measure the initial and final shear strengths of the mud.

Table 2 Basic physical properties of test soil

\begin{tabular}{ccccc}
\hline Gravity & Natural & Liquid & Plastic & \\
specific & Water & limit & limit & Plastic \\
$G_{S}$ & content & $(\%)$ & $(\%)$ & lndex $I_{p}$ \\
& $(\%)$ & $w_{L}$ & $w_{P}$ & \\
\hline 2.673 & $89.4-93.1$ & 77.9 & 36.7 & 41.2 \\
\hline
\end{tabular}

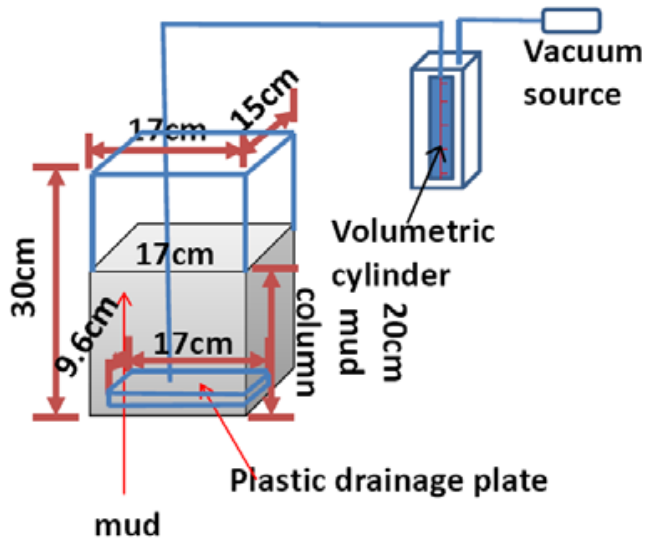

(a) Vacuum

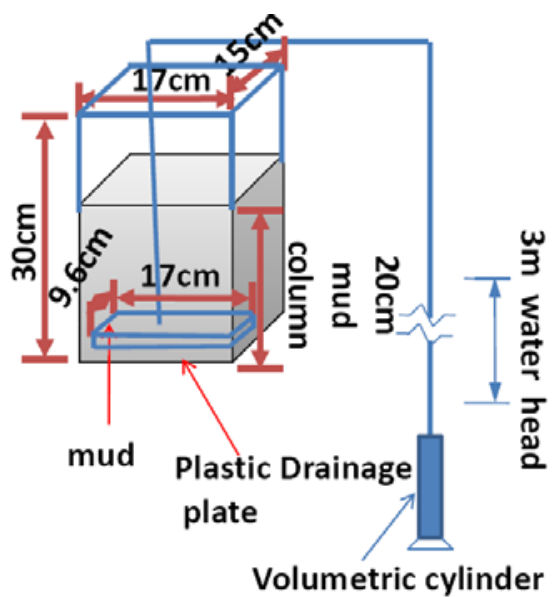

(b) Siphon

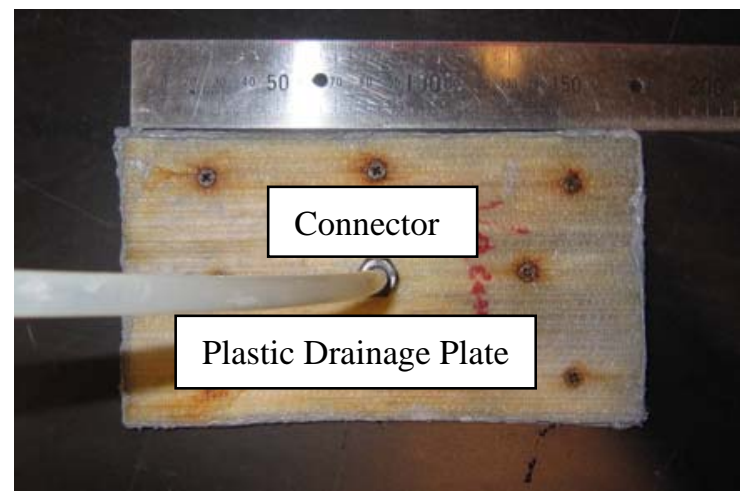

(c) Drainage plate for dewatering Fig.1. Test equipments

4. Test results and analysis

(1) The dewatering comparison efficiency

Figures 2, 3 show the variation of the dewatered volume and water contents with time, respectively. The initial water contents of mud sample for all the tests are $92 \%$. The variations of the dewatering volumes with the time in the vacuum and siphon conditions show no distinct difference in the initial 20 hrs. However, the dewatered volume with vacuum method becomes greater than that with siphon method gradually. Finally, the dewatering in the siphon test is basically stopped, whereas the vacuum dewatering is still slowly developing. As illustrated in Table 3, after 100 hrs dewatering, the water contents for tests $\mathrm{V}-1, \mathrm{~V}-2$ decrease to $53.2 \%, 53.8 \%$, the dewatered volume is about $38.8 \%, 38.2 \%$ of the total involved water in the mud, whereas for tests $\mathrm{S}-1, \mathrm{~S}-2$ the water contents decrease to $59.0 \%, 61.5 \%$, and the corresponding dewatered volume is about 33.0\%, 30.5\% of the total involved water in the mud, respectively. The comparative test results show that at the beginning of the dewatering process, the efficiency with the vacuum and siphon methods exhibit no significant differences. However, as the dewatering proceeds, dewatering efficiency by the siphon method shows less significance than that by the vacuum method. It may account for this phenomenon that the alleviation of the siphon water head with more bubble due to the decrease of the water content. The final water contents of all the siphon tests are slightly less than the liquid limit of the tested mud. It could be due to the following reasons. When the water content is below the liquid limit, the cracks develop progressively, and then the drainage plate would expose in the atmosphere through the cracks and little water head would be remained for generating the siphon dewatering pressure. It may be inferred that the siphon method is specifically efficient for dewatering the dredged mud with relatively high water content, which is generally greater than the liquid limit. 


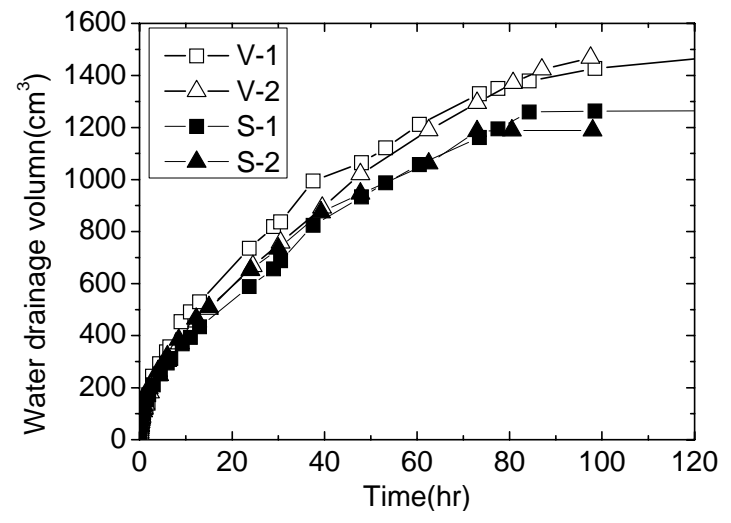

Fig.2. The variation of the water drainage volume with time in the vacuum and siphon tests

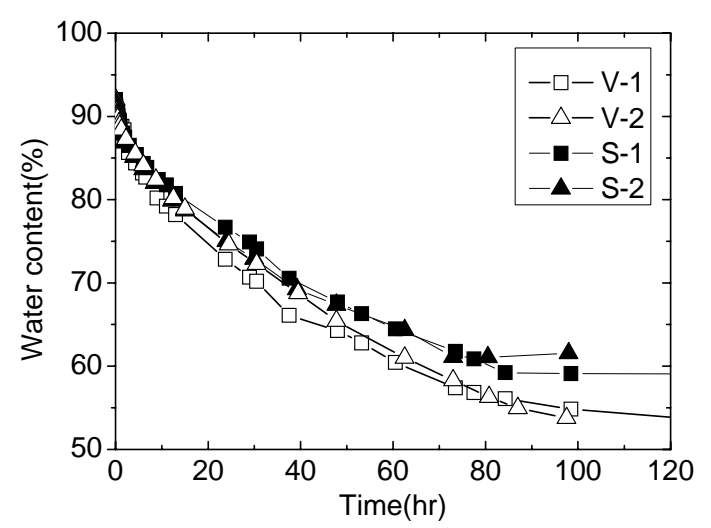

Fig.3. The variation of the water contents with time in the vacuum and siphon tests

Table 3 The final water drainage volume in the vacuum and siphon tests

\begin{tabular}{|c|c|c|c|}
\hline $\begin{array}{c}\text { Test } \\
\text { name }\end{array}$ & $\begin{array}{c}\text { Initial } \\
\text { dewatering } \\
\text { pressure }(\mathrm{kPa})\end{array}$ & $\begin{array}{c}\text { Initial } \\
\text { water } \\
\text { content } \\
(\%)\end{array}$ & $\begin{array}{c}\text { Final } \\
\text { water } \\
\text { content } \\
(\%)\end{array}$ \\
\hline $\mathrm{V}-1$ & \multirow{4}{*}{30} & \multirow{4}{*}{92} & 53.2 \\
\hline $\mathrm{V}-2$ & & & 53.8 \\
\hline S-1 & & & 59.0 \\
\hline S-2 & & & 61.5 \\
\hline
\end{tabular}

(2) The dewatering comparison of the effectiveness

In order to investigate the dewatering effectiveness, the final water content profiles between the vacuum and siphon dewatering methods are compared, as shown in Figure 4. The mud samples for the water contents were taken at the right center of the cross-section in every $3 \mathrm{~cm}$ vertically. The trend lines of the water content profile for vacuum (test V-1 and V-2) and siphon (tests S-1 and S-2) are also illustrated, respectively. The water contents with the two methods generally increase significantly with the depths, whereas the water content with vacuum method is approximately $5 \%$ greater than that with siphon at the same depth. However, the slope of the trend line for vacuum condition is nearly the same as that for siphon condition. Comparing with traditional vacuum dewatering method, siphon method exhibits the similar dewatering effectiveness.

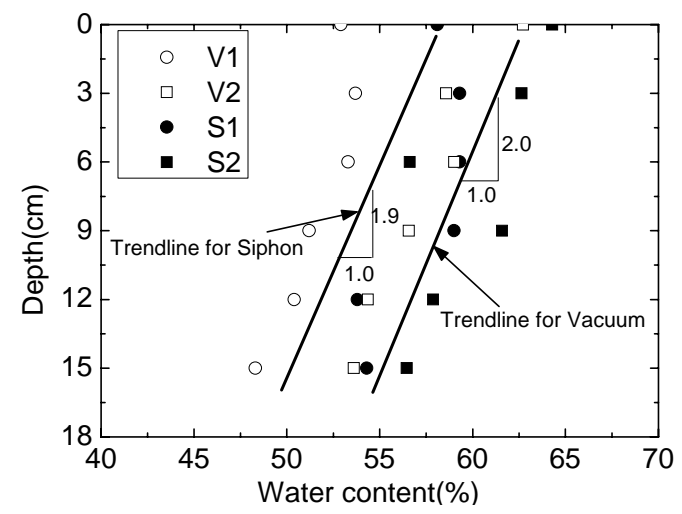

Fig.4. The comparisons of the final water content profiles between the vacuum and siphon dewatering methods

Figure 5 shows the comparisons of the final strength profiles between the vacuum and siphon dewatering methods. The shear strength values of different layers are obtained by the micro-vane shear apparatus. As shown in Fig.5, the shear strength with vacuum and siphon methods shows the similar variation principle, which increases dramatically with the depth. However, as illustrated in Table 4, the shear strengths of the mud at the bottom of the mud column with the vacuum method are slightly greater than that with the siphon method.

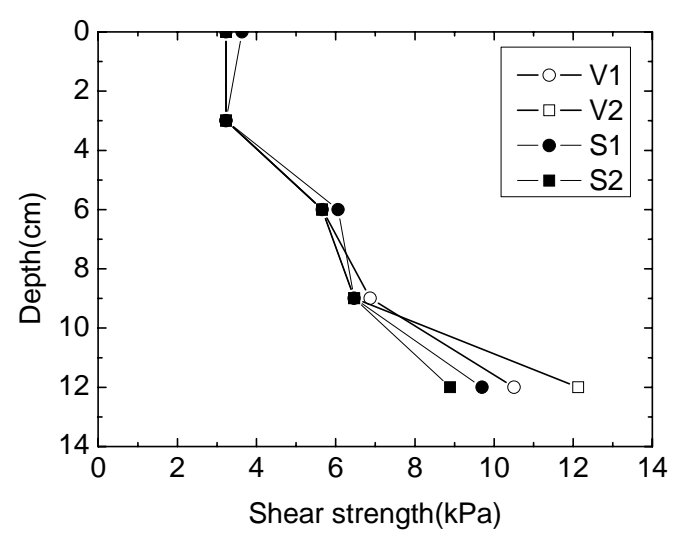

Fig.5. The comparisons of the final strength profiles between the vacuum and siphon dewatering methods 
Table 4 The final maximum and minimum shear strength in the vacuum and siphon tests at the bottom of the mud column

\begin{tabular}{|c|c|c|c|}
\hline $\begin{array}{c}\text { Test } \\
\text { name }\end{array}$ & $\begin{array}{c}\text { Initial } \\
\text { dewatering } \\
\text { pressure }(\mathrm{kPa})\end{array}$ & $\begin{array}{c}\text { Initial } \\
\text { water } \\
\text { content } \\
(\%) \\
\end{array}$ & $\begin{array}{c}\text { Final } \\
\text { Max./Min. } \\
\text { shear } \\
\text { strength }(\mathrm{kPa})\end{array}$ \\
\hline $\mathrm{V}-1$ & \multirow{4}{*}{30} & \multirow{4}{*}{92} & $10.5 / 3.2$ \\
\hline $\mathrm{V}-1$ & & & $12.1 / 3.2$ \\
\hline S-1 & & & $9.7 / 3.2$ \\
\hline S-1 & & & $8.9 / 3.2$ \\
\hline
\end{tabular}

\section{Conclusions}

Through a series of vacuum and siphon comparative tests, the following conclusions can be drawn.

1. The siphon method is specifically efficient for dewatering the dredged mud with relatively high water content, which is generally greater than the liquid limit.

2. Approximate $30 \%$ of water involved in the mud has been dewatered by the siphon tests, suggesting it is effective to dewater the dredged slurry with siphon method.

\section{References}

1) UMEZAKI ET AL. 2004A. A Dewatering method for dredged soil with high water content using gravity and atmospheric pressure. Proceeding of 39th Japan National Conf. on Geotechnical Engineering: 973-974(In Japanese)

2) Jun Tong, Noriyuki Yasufuku, Kiyoshi Omine, Taizo Kobayashi. 2009. Experimental study on an alternative method to dewater the dredged mud by siphon method. The 45th Japanese Geotechnical Symposium. (In press)

3) Jun Tong, Noriyuki Yasufuku, Kiyoshi Omine, Taizo Kobayashi. 2010. Experimentally comparative study on the dewatering of the dredged mud by siphon and vacuum methods.7th International Symposium on Lowland Technology. (In press) 